\title{
Mortalidade materna na perspectiva do familiar
}

\author{
MATERNAL MORTALITY ON THE FAMILY MEMBERS' PERSPECTIVE
}

MORTALIDAD MATERNA EN LA PERSPECTIVA DEL FAMILIAR

\section{Flávia Azevedo Gomes', Ana Márcia Spanó Nakano², Ana Maria de Almeida ${ }^{3}$, Yuriko Kanashiro Matuo ${ }^{4}$}

1 Enfermeira.
Professora Doutora
do Departamento de
Enfermagem
Materno-Infantil e
Saúde Pública da
Escola de
Enfermagem de
Ribeirão Preto da
Universidade de São
Paulo. (EERP-USP)
flagomes@uol.com.br,
2 Enfermeira.
Professora Livre
Docente do
Departamento de
Enfermagem
Materno-Infantil e
Saúde Pública da
EERP-USP.
3 Enfermeira.
Professora Doutora
do Departamento de
Enfermagem
Materno-Infantil e
Saúde Pública da
EERP-USP
4 Obstetriz.
Professora
Associada
Aposentada do
Departamento de
Enfermagem
Materno-Infantil e
Saúde Pública da
EERP-USP

\section{RESUMO}

A mortalidade materna é um dos indicadores do desenvolvimento de saúde e social de um país. É uma tragédia para a família, pois a morte da mãe priva a criança da amamentação e do contato materno, e pelo fato de caber à mulher manter a unidade da família. Este estudo teve como objetivo compreender o significado da morte atribuído por familiares das mulheres falecidas por causas maternas. A população foi constituída por dez familiares de sete mulheres que morreram durante $o$ ciclo grávido-puerperal no município de Ribeirão Preto. Realizamos visitas domiciliares e a coleta de dados foi realizada por meio de entrevista dada pelo familiar da mulher. Para a análise dos dados, utilizamos a análise temática, em que depreendemos três categorias temáticas: significado da morte materna, vivenciando a mortalidade materna na família e vivenciando a mortalidade materna na instituição de saúde. As visitas domiciliares confirmaram que existem fatores coadjuvantes que influenciaram na ocorrência das mortes maternas.

\section{ABSTRACT}

Maternal mortality is one of the health and social development indicators for countries. It is a tragedy for the family, as the death of a mother deprives the child of breastfeeding and maternal contact and also due to the fact that women maintain family unity. This study is aimed at understanding the meaning of death for the family members of women who have died. The population was formed by 10 family members of 7 women who died as a result of maternal problems in the municipality of Ribeirão Preto. The authors visited their homes and collected data through interviews. For analyzing the data the authors used thematic analysis. Three thematic categories were found: the meaning of maternal mortality; living maternal mortality in the family; and living maternal mortality in the health services. The visit confirmed that there are secondary factors that influenced in the occurrence of maternal deaths.

\section{RESUMEN}

La mortalidad materna es uno de los indicadores del desarrollo en salud y social de un país. Es una tragedia para la familia, pues la muerte de la madre priva al niño del amamantamiento y del contacto materno, y por el hecho de que cabe a la mujer mantener la unidad de la familia. Este estudio tuvo como objetivo comprender el significado de la muerte atribuido por familiares de las mujeres fallecidas por causas maternas. La población estuvo constituida por diez familiares de siete mujeres que murieron durante el ciclo grávido-puerperal en el municipio de Ribeirão Preto. Se efectuaron visitas domiciliarias y la recolección de datos fue realizada por medio de entrevista al familiar de la mujer. Para el análisis de los datos, se utilizó el análisis temático, desprendiéndose tres categorías temáticas: significado de la muerte materna, vivenciando la mortalidad materna en la familia y vivenciando la mortalidad materna en la institución de salud. Las visitas domiciliarias confirmaron que existen factores coadyuvantes que influyeron en la ocurrencia de las muertes maternas.

\section{DESCRIPTORES}

Mortalidad materna.

Percepción.

Familia.

\section{KEY WORDS}

Mortalidade materna.

Percepção.

Família.
Perception.

Family. 


\section{INTRODUÇÃO}

A mortalidade materna é apontada como um dos indicadores do desenvolvimento da saúde materno infantil e do desenvolvimento social de um país, refletido na incidência de doenças relacionadas à gravidez e nas condições da assistência pré-natal e do parto. Estudar as taxas e os registros da mortalidade materna é necessário não apenas para se saber sobre os riscos potenciais da gestação, parto e puerpério, mas também para conhecer sobre a saúde da mulher em geral e suas condições sociais e culturais ${ }^{(1-2)}$. Entretanto, acreditamos que refletir sobre os registros quantitativos de óbitos maternos por si só, não permite apreender a realidade de vida dessas mulheres, bem como o meio familiar.

A morte materna é uma tragédia não somente para a mulher, mas também para a sua família, uma vez que a morte da mãe priva a criança da amamentação e do carinho materno, aumentando a mortalidade infantil e a incidência de desnutrição, pois as mulheres cuidam, nutrem e ensinam seus filhos pequenos, além de dar amor nesse período frágil da $\operatorname{vida}^{(3-6)}$.

A ausência repentina e definitiva da mulher no lar constitui um fator de desagregação da família. Nas famílias pobres cabe à mulher importante dimensão de autoridade no seu interior para manter a unidade do grupo $^{(7)}$. A organização doméstica é baseada no princípio tradicional da divisão sexual do trabalho, em que o homem é provedor e a mulher responsável pela manutenção e organização do espaço doméstico. Dentro deste modelo os papéis familiares de gênero e idade são definidos em termos recíprocos e complementares. A ausência da mulher na família se faz sentir também no que tange os recursos econômicos. Estudos têm evidenciado que nas últimas décadas a mulher vem alcançando espaços consideráveis na esfera pública, tendo participação fundamental ou mesmo única no sustento da família. A mulher em idade reprodutiva representa uma parcela importante dos trabalhadores do país, além de exercer responsabilidade no cuidado de toda a família e desempenhar as atividades domésticas ${ }^{(8)}$.

Neste contexto de valoração dos papéis da mulher como ser social, a morte materna torna-se ainda mais significativa em termos dos problemas gerados na família, tanto na esfera emocional - revelada pelo choque, desespero, surpresa, incerteza, não aceitação, medo do futuro; quanto na esfera social - quando a família se depara com o conflito de relações, com a falta de sustentação na transmissão de regras morais e sociais e com o desequilíbrio na condição econômica da família.

Frente a estas considerações torna-se importante o estudo da mortalidade materna em nosso país. A presente pes- quisa é parte de um estudo mais extenso sobre a mortalidade materna, onde foram estudados casos de mortes maternas ocorridas nos anos de 1994 a 1996 de mulheres residentes no município de Ribeirão Preto, Estado de São Paulo ${ }^{(9)}$. Nosso interesse inicial era identificar fatores determinantes e coadjuvantes da mortalidade materna por meio de dados contidos nas fichas do Comitê Municipal de Mortalidade Materna, bem como de prontuários médicos em instituições hospitalares e nas unidades de saúde onde foi realizado o acompanhamento pré-natal. Nesse processo de busca de informações sentimos a necessidade de obter dados complementares que os documentos não nos possibilitavam apreender. Para tanto, decidimos realizar visitas domiciliares buscando um encontro com familiares dessas mulheres, apesar de decorrido mais de um ano após a morte, para identificar revelações prementes acerca da realidade em que tais mulheres viveram, desvelar o que por meio das fontes de dados oficiais não foi possível resgatar, o que se constituiu na fonte de dados que analisamos neste estudo.

Este estudo teve como objetivo compreender a experiência da morte materna na perspectiva dos familiares das mulheres falecidas por causas maternas.

\section{METODOLOGIA}

Foram identificadas 14 mulheres falecidas por causas obstétricas, configurando mortes maternas, que residiam e faleceram no município de Ribeirão Preto - SP, nos anos de 1994 a 1996. As informações acerca do local da ocorrência do óbito e endereço da residência da mulher falecida foram obtidas jun to ao Comitê Municipal de Mortalidade Materna e prontuários médicos.

Visitamos 14 casas; fomos recebidas em nove residências. Em cinco domicílios não foi possível encontrar os moradores, e acreditamos que tenha sido pelo fato das visitas não terem sido agendadas previamente. Estas cinco residências foram visitadas por mais duas vezes, e nos casos onde não houve morador, enviamos via correio uma carta explicando os objetivos da pesquisa e solicitando ao familiar para entrar em contato conosco para que fosse agendada uma visita. Para a realização do contato foram deixados dois telefones disponíveis. As cartas foram enviadas com aviso de resposta (AR), para maior controle deste procedimento. Das cinco cartas que foram enviadas, apenas uma retornou com identificação de que a família havia mudado, quatro retornaram como tendo encontrado o familiar, mas nenhum estabeleceu contato conforme solicitado no conteúdo da carta. Assim, do total de nove casas onde fomos recebidas, duas famílias haviam mudado de endereço, não sendo possível estabelecer o contato. $\mathrm{O}$ recorte da investigação foi, portanto, de dez familiares de sete mulheres falecidas. 
A coleta de dados foi realizada durante a visita domiciliar por meio da entrevista do familiar da mulher falecida, no período de setembro a novembro de 1997.

Para a entrevista, buscamos em primeiro lugar o companheiro da mulher falecida, porém este não foi encontrado em nenhuma das visitas. Em segundo lugar, buscamos irmãos ou pais da mulher falecida. Como terceira opção, um familiar que morasse com a mulher falecida ou que tivesse acompanhado o ciclo grávido-puerperal que levou a mulher ao óbito. Foram entrevistados pai, mãe, irmã, prima e filha da mulher falecida. Em três famílias houve mais de um depoente. As visitas tiveram duração média de 40 minutos. A entrevista foi aplicada em um total de 10 familiares, sendo que os mesmos assinaram o termo de consentimento livre e esclarecido. Não foi obtido recusa à participação por parte dos familiares encontrados. As respostas às questões fechadas e semi-abertas foram registradas no próprio instrumento, as questões abertas foram redigidas imediatamente após o término da visita domiciliar.

O questionário continha perguntas sobre estado marital, número de pessoas com quem morava e o parentesco, se tinha trabalho remunerado e qual era a remuneração, quantas pessoas ajudavam na despesa da casa, número e idade dos filhos, quem assumiu a responsabilidade dos filhos, conhecimento de algum problema de saúde durante a gravidez; motivo pelo qual procurou assistência hospitalar, quem foi o acompanhante e o meio de transporte, se estava em trabalho de parto, se procurou a unidade básica de saúde antes de procurar o hospital, opinião do familiar sobre o porquê da morte, a reação da família frente à morte e opinião acerca da qualidade da assistência recebida.

A análise dos dados foi realizada com base na técnica de análise de conteúdo ${ }^{(10)}$. Utilizamos a análise temática, em que depreendemos temas relacionados ao recorte das falas dos sujeitos e posteriormente fizemos articulações com a literatura científica sobre a mortalidade materna.

O projeto de pesquisa foi analisado e aprovado pelo Comitê de Ética e Pesquisa do Hospital das Clínicas da Faculdade de Medicina de Ribeirão Preto da Universidade de São Paulo.

\section{RESULTADOS E DISCUSSÃO}

\section{Características sócio-demográficas das mulheres falecidas}

Nos anos de 1994 a 1996 no município de Ribeirão Preto, morreram 14 mulheres por causas decorrentes do ciclo grávido-puerperal. As causas dessas mortes foram hemorragia, infecção e eclampsia, configurando as mortes maternas diretas e cardiopatia, rotura de aneurisma e distúrbio hidroeletrolítico e metabólico configurando as mortes maternas por causas indiretas.
Em relação ao perfil das mulheres falecidas, quanto à idade no momento do óbito, esta variou de 16 a 39 anos, sendo que o maior número de óbitos se deu na faixa etária entre 30 e 34 anos. Dois óbitos ocorreram no início da vida reprodutiva.

O estado civil mostrou que houve um maior número de mulheres casadas, seguido de mulheres solteiras. Houve um caso de mulher viúva e em um caso o estado civil esteve ignorado. A visita domiciliar mostrou que a mulher cujo estado civil era viúva vivia com um companheiro.

Do universo de mulheres deste estudo, 10 não tinham trabalho remunerado, em dois casos não foi possível ter acesso a essa informação e duas mulheres tinham trabalho remunerado. $\mathrm{O}$ familiar visitado não soube responder em nenhum dos dois casos, o valor da remuneração deste trabalho.

Quanto à escolaridade, houve quatro casos onde esta informação não foi registrada. Nenhuma mulher possuía nível superior de escolaridade, uma delas havia cursado o ensino médio e nove cursaram o ensino fundamental.

A maioria das mulheres deste estudo vivia com companheiro fixo e quanto à paridade, uma mulher era primigesta, quatro secundigestas, uma tercigesta, sete multigestas e houve um caso ignorado. Quanto ao período do ciclo grávidopuerperal em que ocorreu a morte, encontramos seis óbitos ocorridos na gestação, sendo um deles decorrente do aborto e oito óbitos ocorridos no puerpério, sendo que o tipo de parto foi cesárea em seis casos e vaginal em dois casos. Em relação ao local de ocorrência das mortes, encontramos 13 óbitos em instituições hospitalares e um em domicílio. Quanto ao tipo de instituição hospitalar, 8 óbitos ocorreram em hospital universitário integrado ao Sistema Único de Saúde que constitui-se em referência regional do nível terciário de atenção à saúde; 4 óbitos ocorreram em instituição filantrópica e 1 óbito em maternidade particular conveniada.

Quando analisamos a assistência pré-natal neste estudo, temos que seis mulheres fizeram acompanhamento prénatal; três não fizeram pré-natal e em cinco casos não foi possível obter esta informação.

No momento da coleta dos dados, sete mulheres haviam morrido há três anos, cinco mulheres haviam morrido há dois anos e duas mulheres há um ano. No contato direto com o familiar, as informações quanto às condições de prénatal, sua evolução, os fatores de risco social, biológico e psicológico vieram à tona. Estas visitas nos permitiram obter informações de ordem social e cultural.

A análise dos dados das entrevistas possibilitou a criação de três categorias temáticas, considerando os significados, vivências e situações relacionadas à morte materna ocorrida na família. São elas: significado da morte; vivenciando a morte materna na família e vivenciando a morte materna na instituição de saúde. 


\section{1 - Significado da morte materna}

A morte de uma mulher jovem no parto ou logo após, é trágico para todos: família, profissionais de saúde e para a sociedade. A perda familiar é imensurável, especialmente quando a sobrevivência da criança está ligada à sobrevivência da mãe. Em nossa sociedade, a morte de uma pessoa jovem causa um impacto maior do que a morte de uma pessoa idosa e doente. A idéia subjacente é a de que acidentes ou mesmo a doença em jovens não fazem parte da natureza.

Carregamos o ônus de uma morte prematura e uma sensação de desconforto e raiva quando uma pessoa morre "em um momento errado", ou seja, jovem e sã ${ }^{(11-12)}$.

Ficamos abalados, a gente não esperava que ela morresse assim, tinha uma saúde de ferro, sem vícios, não bebia nunca (caso 2).

Observamos que para este familiar, a morte materna foi compreendida como algo esperado frente a uma situação de doença prévia:

Ela era doente, sempre foi, desde os dez anos, ela sabia que não podia engravidar de novo...aceitamos com tranqüilidade, tinha que acontecer (caso 4).

Há casos em que surge o conformismo, a determinação da morte materna como algo que não poderia ser evitado:

O que o médico pode fazer, ele fez. Socorreu minha filha até a última hora (caso 4).

Acresce-se ao fato da maternidade ser percebida culturalmente como estando a mulher em "estado de graça", evidenciando em como o início de uma vida mostra-se incongruente com a experiência da morte.

Nossa reação foi de pânico, desespero, porque ela foi ganhar nenê, não é, como é que chega a notícia de que ela morreu; nós estávamos nos arrumando para visitar achando que ela estava no quarto. Ainda não entendemos o porquê da hemorragia, falaram hemorragia (caso 7).

A resposta mais comum diante da morte é o medo, indignação e o sentimento de impotência por não poder ser feito nada pela morte do outro. Outra resposta esperada é a negação da morte e da espiritualidade, pelo fato do aceitável ser apenas o que se pode ver e palpar ${ }^{(13)}$.

Falamos em minha mãe todos os dias; ontem à noite, falamos de sua morte, que ela poderia estar aqui (caso 3).

\section{2 - Vivenciando a morte materna na instituição de saúde}

O sistema de saúde no país ressalta a necessidade de integração entre os três períodos de assistência à mulher no ciclo grávido-puerperal (pré-natal, parto e puerpério). Contudo, essa não é uma realidade a ser generalizada nos diferentes contextos de assistência no país ${ }^{(11)}$. Esse fato faz com que a assistência no período pré-natal seja feita sem retaguarda hospitalar e a impossibilidade de acesso às informações, de forma contínua e integral, em qualquer um destes períodos, fragiliza a assistência, e expõe a mulher a riscos de vida. É necessário reverter a dissociação entre a assistência pré-natal e assistência ao parto e ao puerpério, buscando o princípio da integralidade da assistência à mulher e à criança

Outra questão a ser levantada é a desigualdade na oferta dos serviços de saúde nos municípios. O déficit de leitos públicos é maior nas regiões mais periféricas, não só em relação ao atendimento de gestantes saudáveis, mas também, para gestantes com complicações que exijam atendimento complexo. Este fato, ainda que não tenha provocado alteração na cobertura de partos hospitalares, origina uma peregrinação de gestantes em busca de assistência adequada. A peregrinação em busca de um local para dar à luz não foi identificada neste estudo, uma vez que o município de Ribeirão Preto conta com a central de vagas de obstetrícia, encaminhando as gestantes às maternidades credenciadas ao SUS, qualquer que tenha sido a Unidade de Saúde onde a mulher tenha feito o acompanhamento pré-natal.

Embora esta não seja uma realidade do município onde se deu este estudo, nota-se que a idéia de que a mulher não terá uma instituição hospitalar para dar à luz é um fator evidenciado pelos familiares. Nesse sentido a procura pela assistência se deu pelo reconhecimento de sinais e sintomas indicativos de trabalho de parto ou mesmo pela percepção de gravidade diante de manifestações apresentadas na gestação, parto ou no puerpério.

Não procurou a unidade básica de saúde, sendo atendida imediatamente à sua chegada ao hospital (caso 2).

Entrou em trabalho de parto, a bolsa rompeu há mais de uma hora. Foi acompanhada pela filha, de ambulância. A ambulância demorou mais de uma hora para chegar, ela não falou que a mãe estava em trabalho de parto. Não procurou a unidade básica de saúde antes de procurar o hospital (caso 3).

Dores de cabeça, pressão alta. Foi acompanhada pela prima e o meio de transporte foi a ambulância (caso 2).

Procurou a unidade de saúde porque passou mal, estava delirando, com fraqueza e dor de cabeça. Não estava em trabalho de parto, foi acompanhada pelo marido, indo de carro. Procurou mais de uma instituição hospitalar (caso 6).

A disponibilidade de serviços não assegura, por si só, que a mulher terá acesso a eles. Autores afirmam que há barreiras em relação à qualidade do cuidado, informação, acessibilidade e utilização dos serviços de saúde. Estas podem estar relacionadas à desinformação que impede as mulheres de reconhecerem seus direitos e terem acesso à prevenção e tratamento apropriados. Adesinformação impossibilita as mulheres de exigirem atendimento adequado nos serviços de saúde ou de usá-los de forma a contemplar suas necessidades ${ }^{(1)}$. 
O acesso aos serviços de saúde é determinado por fatores físicos, que incluem a proximidade dos serviços de saúde de onde a mulher vive e viabilidade de transporte. Fatores econômicos, dificuldade para conseguir medicamentos, necessidade de cuidar de crianças, da casa, cuidar da alimentação também são definidos como barreiras relacionadas ao acesso das mulheres ao serviço de saúde. Por outro lado, a existência de facilidade de acesso físico não garante o comparecimento da mulher ao serviço de saúde. Há inconvenientes relacionados ao horário das consultas, dificuldade de comunicação com os profissionais de saúde, relutância em aderir a algum programa de saúde, como pré-natal, planejamento familiar, cursos de gestantes. Existem fatores socioculturais que dificultam o acesso de mulheres ao serviço de saúde, como por exemplo, o cuidado do outro em detrimento do cuidado de si e ou a dependência financeira de outros familiares ${ }^{(1,14)}$.

O fato de que na maioria dos países em desenvolvimento os serviços de saúde estejam mal adaptados às necessidades da mulher pode ser explicado, em parte, pelo fato de que a mulher ainda não consegue fazer-se ouvir. As condições de desigualdade social entre homens e mulheres acarretam riscos específicos para a saúde das mulheres. O nível educacional, a participação no trabalho formal, estado civil, estão associados à saúde reprodutiva das mulheres ${ }^{(5)}$. A mortalidade materna está ligada à pobreza econômica das mulheres, à falta de acesso à informações e ausência de serviços de saúde adequados ${ }^{(15)}$. O fato de que vários fatores contribuem para a mortalidade materna, sugere que qualquer estratégia, para ser eficaz, requer um enfoque amplo, baseado em um modelo de atenção primária da saúde. Seu objetivo incorporaria um maior número de serviços de saúde materna e planejamento familiar no nível primário. Para a saúde materna, não depende melhorar somente os serviços de saúde e sim outras condições sociais e econômicas, com maior nível de escolaridade, saneamento e nutrição.

\section{3 - Vivenciando a morte materna na familia - dimensionado perdas}

Pelo fato da mortalidade materna no Brasil poder ser evitada em aproximadamente $90 \%$ dos casos e devido ao impacto que a morte de uma mãe jovem produz na estrutura e na dinâmica familiar, evitar estas mortes significa também zelar pela família, impedindo que esta se desintegre por uma morte precoce. Configura-se ainda perda econômica para a família uma vez que a mulher seria um membro ativo no esquema de produção e financeiro da família ${ }^{(5,16)}$. Não se pode ficar alheio a situações de mortes que são evitáveis e ligadas ao atendimento no pré-natal, parto ou puerpério.

Muito mal, a família se desmantelou. Agora, depois de três anos, é que estamos nos reestruturando, foi bom a $\mathrm{M}$. (filha que nasceu na ocasião de sua morte) ter vivido e ficado com a gente, dá alegria (caso 6).
Depois da morte foi ótimo, mandaram a assistente social, mas na hora do parto... bom, foi um erro e dizem que todos podem errar, que é humano...(caso 3 ).

As mulheres são responsáveis por mais da metade da produção agrícola nos países em desenvolvimento e constituem um terço da força de trabalho oficial destes países. São ainda responsáveis pelo trabalho doméstico e criação dos filhos. A família sofre não apenas a perda da mãe ou o pilar da família, mas também com o fato que o bem estar e a sobrevivência de suas crianças estão sob sua responsabilidade. A morte de uma mulher em uma família pobre é uma "sentença de morte virtual" para suas crianças ${ }^{(17-18)}$.

A desestruturação familiar é uma outra questão social relacionada à mortalidade materna. Com a morte da mãe, muitas vezes os filhos menores são entregues entre os familiares. As crianças, além de viverem a perda da mãe, deparam-se com a separação dos irmãos e do pai ${ }^{(15)}$.

Assim, o desamparo parece ser o sentimento predominante nas falas dos familiares, neste estudo, que permanecem com o sentimento de injustiça e evitabilidade da morte materna.

Não sei. Acho que foi pelo susto ou desgosto de saber que o nenê tinha morrido e por não terem feito cesárea nela (caso 2)

Por negligência médica. A pessoa do banco de sangue não liberou o sangue que a $C$. precisava, o médico falou que se responsabilizava, mas a pessoa não liberou. Falaram que ela precisava ter feito histerectomia, mas não fizeram a tempo (caso 7).

Analisando o significado atribuído pelos familiares das mulheres falecidas, sobre a assistência à saúde recebida, evidencia-se as marcas da negligência que estão contidas nos relatos de que houve espera em demasia pela assistência recebida.

O despreparo dos profissionais e a desintegração do sistema de saúde para a mulher no ciclo grávido-puerperal gera riscos mesmo para as mulheres mais saudáveis ${ }^{(19)}$. Contribuindo para agravar esse quadro, em muitas cidades do país, não há um sistema de referência e contra-referência organizado que vincule o pré-natal ao parto e possibilite a assistência adequada em situações de risco. O pré-natal realizado com um número insuficiente de consultas ou com atendimento de baixa qualidade contribui para a falta de diagnósticos de gestação de risco, aumentando a ocorrência de agravos. Reitera-se que o acompanhamento pré-natal deve ser estruturado a partir das necessidades biológicas e das circunstâncias sociais da população usuária ${ }^{(2)}$.

Os profissionais de saúde e o sistema de saúde estão sob a mira, no que diz respeito à reação de familiares perante a morte materna. 
Ficamos com vontade de fazer qualquer loucura, processar os médicos (caso 3).

Porque não podia fazer força para ter o nenê de parto normal, por causa do coágulo que tinha na cabeça, e teve o filho praticamente sozinha, no hospital, lá sentada (caso 6).

Foi péssima. Não voltaríamos lá de jeito nenhum (caso 7).

Um estudo realizado analisou a evitabilidade da morte e a qualidade da assistência na Holanda, Reino Unido e França, concluindo que a inexperiência dos profissionais de saúde envolvidos em cuidar da doença e a demora em admitir a gravidade do caso são fatores que contribuem para a morte ${ }^{(20)}$. Fato esse percebido, neste estudo, por familiares das mulheres falecidas quando afirmaram acerca da qualidade da assistência recebida:

Foi péssima...por culpa dos médicos que a deixaram sofrer, não fizeram a cesárea antes. Por causa da pressão alta, ela não podia ter o nenê de parto normal, precisava de cesárea logo para não morrer (caso 3).

A assistência é boa, foi de ambulância, mas acho que o hospital demorou muito para fazer a cesárea, tinham que ter abaixado a pressão com remédios (caso 2).

O acompanhamento deficiente ao trabalho de parto e ao puerpério, assistência tardia a complicações decorrentes do trabalho de parto e parto imputam ao atendimento hospitalar uma quantia significativa de responsabilidade pelo óbito materno.

\section{CONSIDERAÇÕES FINAIS}

Ainda que dentro de um mesmo padrão social, nem todas as mulheres estão expostas a riscos semelhantes: algumas apresentam maior probabilidade de morrer ou sofrer agravos do que outras. Diversos fatores biológicos e relacionados ao estilo de vida aumentam as chances de que sobrevenham complicações que possam colocar em risco a vida da mulher.

\section{REFERÊNCIAS}

(1) Abouzahar C, Wardlaw T, Stanton C, Hilk K. Maternal mortality. World Health Statist Q. 1996;49(2):77-87.

(2) Rezende CHA, Moreli D, Rezende IMAA. Mortalidade materna em cidade de médio porte, Brasil, 1997. Rev Saúde Pública. 2000;34(4):323-8.

(3) Bonciani IRDF, Spink MJP. Morte por AIDS ou morte materna: a classificação da mortalidade como prática social. Cad Saúde Pública. 2003;19(2):645-52.
Todas as visitas vieram confirmar que existem fatores coadjuvantes que influenciaram na ocorrência das mortes maternas. A idéia inicial das visitas domiciliares era complementar as informações para se obter uma melhor qualidade dos dados a serem analisados. $\mathrm{O}$ que foi encontrado, foi surpreendente e paradoxalmente rico: o cotidiano das mulheres deste estudo, continha as revelações mais interessantes sobre questões prementes da realidade em que viveram. Destas visitas, ficou uma pergunta: como a maioria vive ou até mesmo sobrevive em meio a situações de tamanho infortúnio? Pode-se tentar responder a partir de que a vida existe apesar das condições sociais e de saúde as quais as mulheres em nosso meio são submetidas.

Houve a possibilidade de ressaltar o que a literatura revisada mostrou em relação à desestruturação familiar que ocorre com a morte da mulher. O quanto é difícil manter a mesma característica da família após a morte da mãe.

Refletindo sobre as situações apontadas temos a considerar que os fatores intervenientes que tem possibilitado a manutenção das altas taxas de mortalidade materna, perpassam pela qualidade da assistência pré-natal e durante o trabalho de parto e parto e tem uma inter-relação com a gestante, com os profissionais que a assiste e às instituições envolvidas.

A instituição nem sempre está preparada para a assistência obstétrica e há casos de falta de recursos como sangue e derivados. Há ainda lacunas na formação obstétrica de alguns profissionais e algumas gestantes apresentam deficiência nutricional, psicológica e social que contribuem com os fatores elencados.

Conhecer a história das mortes maternas deve despertar nas autoridades a conscientização desta situação a fim de priorizar o atendimento integralizado à saúde da mulher e ainda alertar a população, especialmente as mulheres para a exigência de um atendimento efetivo para a promoção da saúde.

(4) Brasil. Ministério da Saúde. Secretaria de Políticas de Saúde. Área Técnica de Saúde da Mulher. Manual dos Comitês de Mortalidade Materna. 2a ed. Brasília; 2002.

(5) Bratti C, Amador N. Mortalidad de la mujer en edad fertil en Costa Rica, 1987-1989. Bol Ofic Sanit Panam. 1995;118(3):191-200.

(6) Taha TE, Miotti P, Liomba G, Dallabetta G, Chiphangwi J. HIV, maternal death and child survival in Africa [letter] AIDS. 1996;10(1):111-2 
(7) Sarti CA. A continuidade entre casa e rua no mundo da criança pobre Rev Bras Cresc Desenv Hum. 1995;5(1/2):39-47.

(8) Albuquerque M. Mortalidade materna em Recife: avaliação da subnumeração de estatísticas oficiais. Cad Saúde Pública. 1997;13(1):59-65.

(9) Gomes FA, Matuo YK, Carvalheiro CD. Mortalidade materna no município de Ribeirão Preto: fatores determinantes e coadjuvantes. J Bras Ginecol. 1998;108(11/12):405-12.

(10) Bardin L. Análise de conteúdo. Lisboa: Edições 70; 1995.

(11) Simões VMF, Silva AAM, Bettiol H. Características da gravidez na adolescência em São Luis, Maranhão. Rev Saúde Pública. 2003;37(5):559-65.

(12) Kastenbaum R, Aisemberg R Psicologia da morte. Trad. de Adelaide Petters Lessa. São Paulo: Pioneira; 1983.

(13) Kóvacs MJ Morte e desenvolvimento humano. São Paulo: Casa do Psicólogo; 1992,

(14) Cutts FT. Child and maternal mortality during a period of conflict in Beira City, Mozambique. Int J Epidemiol. 1996;25(2):349-56.
(15) Araújo MJO. Campanha internacional contra a morte materna completa 13 anos. J Rede Saúde. 2000;20:3-4.

(16) Martins-Costa S, Ramos JG, Cericatto R, Schlatter D, Petry SM. Causas da mortalidade materna no Hospital de Clínicas de Porto Alegre - RS. Análise de 15 anos. Rev Bras Ginecol Obstetr. 1997;19(7):507-13.

(17) Pittman P, Hartigan P. Gender inequity: an issue for quality assessment researchers and managers. Health Care Women Int. 1996;17(5):469-86.

(18) Sanches S, Gebrim VLM. O trabalho da mulher e as negociações coletivas. Estud Av. 2003;17(49):99-116.

(19) Berquó E. Sexo \& Vida: panorama da saúde reprodutiva no Brasil. Campinas: Edunicamp; 2003.

(20) Bouvier-Colle MH. Reasons for the underreporting of maternal mortality in France, as indicaterd by a survey of all deaths among women of childbearing age. Intern $\mathrm{J}$ Epidemiol. 1991;20(3):717-21. 